РЕЦЕНЗИИ. ОТКЛИКИ НА ПУБЛИКАЦИИ ЖУРНАЛА COMMENTS AND REVIEWS ON ARTICLES PUBLISHED IN THE JOURNAL

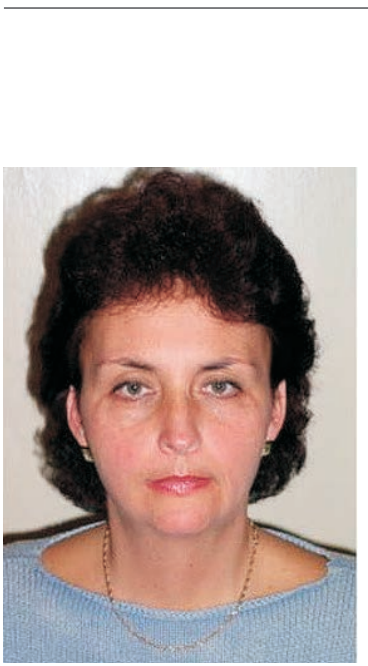

УДК 80/81
DOI 10.17150/2308-6203.2017.6(4).643-649

\begin{abstract}
Новикова Марина Львовна
Доктор фрилологических наук, професссор

кафедра русского языка юридического института,

Российский университет дружбы народов, РУДН, 117198,

Россиская Федерация, г. Москва, ул.Миклухо-Маклая, 6,

e-mail: novikovamarinalvovna@yandex.ru
\end{abstract}

Marina L. Novikova

DSc. in Philology, Full Professor

Russian Language Department, Institute of Law,

Peoples' Friendship University of Russia, 6 Miklukho-Maklaya

St., Moscow, 117198, Russian Federation,

e-mail: novikovamarinalvovna@yandex.ru

\title{
МЕДИАЛОГИЯ КАК КОМПЛЕКСНАЯ НАУКА (прагматический потенциал лингвистических исследований)
}

\footnotetext{
Аннотация. Рецензия является откликом на статью А. П. Суходолова и М. П. Рачкова «Медиалогия - наука будущего», посвященную предварительному подведению итогов дискуссии о теории средств массовой информации, анализу широкого спектра оценок современного состояния теоретических и эмпирических исследований медиасореры, нашедших свое убедительное и аргументированное воплощение в публикациях на страницах журнала «Вопросы теории и практики журналистики». Эти проблемы являются объектом пристального внимания ведущих специалистов - исследователей журналистики и средств массовой информации. Дискуссия о терминологии и понятийном аппарате теории массмедиа показывает, насколько актуальным и необходимым является участие в ней представителей лингвистики, изучающих язык в разных парадигмах научного знания. Автор обращается к проблемам прагматического потенциала лингвистических исследований медиалогии как комплексной науки, высвечивая ее новые грани и аспекты исследования.

Ключевые слова. Медиалогия, медиасфера, информационное общество, язык как коммуникативная система, лингвистика и журналистика, прагматика, информационное пространство.

Информация о статье. Дата поступления 05 сентября 2017 г.; дата принятия к печати 09 октября 2017 г.; дата онлайн-размещения 30 октября 2017 г.
} 


\title{
MEDIOLOGY AS A COMPLEX SCIENCE (Pragmatic Potential of Linguistic Research)
}

\begin{abstract}
The review is a response to the paper by A. P. Sukhodolov and M. P. Rachkov entitled "Mediology as a science of the future», devoted to making preliminary conclusions of the discussion on the media theory, interpretation of modern theoretical and empiric media sphere research assessment that found its implementation in publications on the pages of Theoretical and Practical Issues of Journalism. The problems of mass media theory are an object of journalism and mass media specialists' scrutiny. The discussion of the mass media terminology shows how important and relevant it is to have linguists studying various scientific paradigms involved into it. The author explores the problems of linguistic research of the complex media science pragmatic potential, putting an emphasis on its new sides and aspects of research.

Keywords. Mediology, media science, media sphere, information society, language as a communicative system, linguistics and journalism, pragmatics, information space.

Article info. Received September 05, 2017; accepted October 09, 2017; available online October 30, 2017.
\end{abstract}

Невиданные в прежние эпохи изменения, детерминированные объединением, сплетением онлайн и оффрлайн коммуникаций средств массовой информации, требуют системного изучения и теоретического обоснования, осмысления информационного пространства, глобальной медиасреды. «Современная журналистика как форма коммуникативной практики, развивающаяся совместно с глобальным проектом информационного общества, приобретает ряд качественно новых свойств $<\ldots>$ на фоне формирования новой информационной парадигмы, характеризующейся усилением коммуникативного аспекта журналистской деятельности» [1, с. 11-12]. Единое информационное пространство создано разными медиапотоками: печатью, радио, телевидением, Интернетом. Теория коммуникации активно разрабатывается многими учеными, формулировки «the medium is the message» («средство информации является сообщением») и «global village» (М. Маклюэн) («глобальная деревня» - о современном мире, в котором люди, активно используя современные технологии, живут в едином коммуникативном пространстве) очень точно отражают специфику современных информационных процессов. Глобализация и интеграция - два взаимосвязанных процесса, во многом определяющих бытие современного человека, научно-технические новации предоставляют ему невиданную прежде коммуникативную и пространственную мобильность.

В статье А. П. Суходолова и М. П. Рачкова «Медиалогия - наука будущего» [2, с. 267-286], по существу своему являющейся продолжением дискуссии, начатой журналом в 2016 г. [3, с. 6-13] и фокусирующей внимание на важнейших вопросах систематизации и структурирования 
накопленных знаний о массмедиа, есть много новых идей и ярких наблюдений. Принципиально интересна избранная авторами структура статьи, оригинально отражающая итоги дискуссии, проводимой на страницах журнала, и убедительно показывающая, что у российской научной школы СМИ и журналистики есть безусловный потенциал в создания науки о массмедиа, который должен активно использоваться в самом ближайшем будущем. Статья вызывает большой интерес и желание обращаться к ней вновь и вновь в силу целого ряда причин, обусловленных, в том числе, и более широкой постановкой вопроса о создании обобщающей науки о массмедиа медиалогии. Эти и многие другие вопросы диктуют необходимость обсуждения проблем теории средств массовой информации, они являются объектом пристального внимания признанных авторитетов в области теории журналистики в разных уголках России и за рубежом, исследователей журналистики и средств массовой информации.

Разнообразная палитра мнений о процессе теоретических и эмпирических исследований медиасферы, широкий спектр оценок современного состояния медиаисследований нашли свое убедительное и аргументированное воплощение в публикациях на страницах журнала, вызвавших широкий резонанс у профессионального журналистского сообщества. Процесс дигитализации, перевода информации в цифровую форму, ознаменовал начало новой эпохи в развитии личности, общества, культуры. Большое внимание в статье уделено проблемам оперативного теоретиче- ского осмысления современной системы СМИ.

Особенный интерес вызывает постановка вопроса о создании обобщающей науки о массмедиа медиалогии, представляющей собой синтез теории средств массовой информации как динамической системы, теории журналистики как массово-информационной деятельности СМИ и журналистов и дополняющей их теории управления медиасистемами и медиапроцессами. В статье обосновано, что по своей социальной значимости медиалогия выдвигается в разряд самых перспективных и востребованных научных направлений в мире. «Поэтому мы называем медиалогию наукой будущего», - с полной уверенностью констатируют А. П. Суходолов и М. П. Рачков, в то же время отмечая, что сейчас следует говорить только о процессе становления этой науки, поскольку она не результировалась еще ни в четко оформленную отрасль научного знания, ни в учебники, представляющие систематизацию этого знания. Уточняя и развивая заявленные ранее идеи систематизации и структурирования накопленных знаний о массмедиа, авторы статьи убедительно доказывают, что оперативное познание медиасистемы как одной из самых высокоскоростных динамических систем невозможно без применения математических методов, что, образно говоря, математика, подобно лингвистике, должна стать сестрой журналистики.

Влияние информационного поля средств массовой информации на человеческое сознание огромно, это детерминирует необходимость «осмыслить роль языка средств массо- 
вой информации в новых условиях с учетом процессов, происходящих в обществе, культуре, политике, идеологии» $[4$, с. 14$]$.

Полностью разделяя позицию А. П. Суходолова и М. П. Рачкова о необходимости союза лингвистики и журналистики, подчеркнем, что язык является не просто средством для обмена информацией, «он особая форма взаимодействия людей, механизм получения и систематизации информации, средство репрезентации действительности, ее осмысления, инструмент воздействия, особый вид социально-информационных связей, средство оптимизации всех видов деятельности человека» [5, с. 255]. Дискуссия о терминологии и понятийном аппарате теории массмедиа показывает, насколько актуальным и необходимым является участие в ней представителей лингвистики, изучающих язык в разных парадигмах научного знания как коммуникативную систему, ее структуру и фрункции, специфику аккумуляции общественно значимой информации, особенности обмена информацией между людьми. На лингвистических исследованиях базируются междисциплинарные исследования по теории аргументации, которые рассматриваются с привлечением семантических и семиотических методик.

Изучение общения людей и обращение разных отраслей знания к анализу языка приобретают особое значение. Использование языка как средства воздействия и убеждения активизируют исследование его прагматического аспекта, в рамках которого изучаются отношения знаков к субъектам, которые их производят и интерпретируют. Язык как ког- нитивный инструмент, т. е. «система знаков, играющих роль в репрезентации (кодировании) и трансформировании информации» [6, с. 12], является средством формирования и существования знаний и представлений человека о мире, отражает в слове результаты его познавательной деятельности.

Медиалогия - наука, изучающая различные аспекты развития медиа, характер, типы, формы, результаты воздействия на общество, как и любая научная дисциплина, имеет свою систему научных категорий и понятий, собственную терминологию. Следует подчеркнуть, что в настоящее время продолжается формирование терминосистем многих областей и разделов научного знания, особенно междисциплинарных и активно развивающихся, как следствие отражения быстро меняющейся научной и социокультурной ситуации. Термины играют важную роль: они классифицируют и организуют новые научные знания и информацию, становятся носителем и хранителем фрагмента информации, которая имеет свою ценность в особой понятийной системе. Образование нового научного понятия на основе уже существующего языкового материала часто связывают с «новым пониманием» предмета [7, с. 3].

Терминология медиалогии, повидимому, в настоящее время не является оптимально организованной, семиотически безупречной, она является открытой системой, которая постоянно пополняется и видоизменяется, динамичное развитие и языковые контакты приводят к интенсивному образованию соответствующих понятий. Необходимо 
осознание комплексного, разноаспектного характера терминосистемы медиалогии, ее систематизация в аспекте структурированности, функциональной связанности, полифункциональности, развивающейся целостности: медиа, массмедиа, медийность, медиатизация, медиальность, медиалогия, медиасистема, медиапространство, медиасреда, медиареальность, виртуальность, виртуальная реальность, неосфера, инфосфера, киберсфера, медиапроцесс, медиаобъект, медиасубъект, киберобъект, киберсубъект, медиадискурс, массмедийный дискурс, медиатекст, медиакультура, медиафилософия, медиаполитика, медиарынок и др. Задачи лингвистического упорядочения терминологии видятся в следующем: изучение и анализ реального словоупотребления; систематизация и отбор терминологии, описание ее в словарях терминов; сопоставление национальных терминосистем 8 многоязычных терминологических словарях.

В фрилософско-гносеологическом определении термины являются элементами научного аппарата теорий и концепций, описывающих различные области знаний и деятельности, наряду с другими средствами познания. Термин «медиалогия», обозначающий отрасль науки, должен представлять собой такую единицу наименования, которой следует приписывать определенное понятие, она должна быть соотнесена с другими наименованиями, образуя вместе с ними терминологическую систему. Термин, в отличие от обычного слова, всегда выражает строго фиксированное понятие, он должен быть краток, лишен многозначности, синонимии, омонимии. Термин также является и объектом семиотики, представляя собой знаковое понятие медиалогии как определенной специальной области знания и деятельности. Таким образом, термин «медиалогия» как знак вступает во все семиотические отношения: синтактика (отношение знака к знаку), семантика (отношение знака к значению) и прагматика (отношение знака к человеку). Выражая специальное понятие, термин становится носителем и хранителем фррагмента информации, которая имеет свою ценность в особой понятийной системе, и в этом смысле термин являет собой когнитивно-информационную структуру, в которой аккумулируется выраженное в конкретной языковой форме профессиональнонаучное знание. Важным является и вопрос информационной емкости того или иного термина, его понятийно-семантической структуры, иначе - «совокупности значений термина, «доставляющих» данную терминологическую информацию. Такое изменение информационной емкости термина обусловливается прогрессом общественного знания, что в результате и объясняет дальнейшую модификацию соответствующих понятий» $[8$, с. 56].

Статья «Медиалогия - наука будущего» имеет большую методологическую ченность. Она открывает новые горизонты изучения медиалогии, предлагает задуматься и о том, что рождение новых форматов в языке и стиле требует систематизации и корректирования терминологического аппарата, нацеливая на рассмотрение этой проблемы сквозь призму прагматического потенциала линг- 
вистических исследований. Итоги дискуссии, обсуждение ее спорных моментов, яркая мозаика позиций и мнений, дальнейшая перспектива продолжения дискуссии о создании обобщающей науки о массмедиа, использование лингвистических исследований в такой динамичной и постоянно развивающейся сфере деятельности как журналистика, изучение особенностей функциониро- вания языка в современном информационном обществе являются убедительным свидетельством плодотворных научных поисков и открытий, четко и последовательно отражают высокую миссию журнала - объединение усилий научно-образовательной общественности Российской Федерации и зарубежных стран в исследованиях теории и практики журналистики.

\section{СПИСОК ИСПОЛЬЗОВАННОЙ ЛИТЕРАТУРЫ} 272 c.

1. Калмыков А. А. Медиалогия интернета / А. А. Калмыков. - М. : Либроком, 2013. —

2. Суходолов А. П. Медиалогия - наука будущего (приглашение к продолжению дискуссии, начатой журналом в 2016 г.) / А. П. Суходолов, М. П. Рачков // Вопросы теории и практики журналистики. - 2017. - Т. 6, № 3. - С. 267-286. - DOI 10.17150/23086203.2017.6(3).267-286.

3. Суходолов А. П. К созданию теории средств массовой информации: постановка задачи / А. П. Суходолов, М. П. Рачков // Вопросы теории и практики журналистики. 2016. - T. 5, № 1. - C. 6-13. — DOI: 10.17150/2308-6203.2016.5 (1).6-13.

4. Солганик Г. Я. О структуре и важнейших параметрах публицистической речи (языка СМИ) / Г. Я. Солганик // Язык современной публицистики : сб. ст. - М. : Флинта; Наука, 2005. - С. 13-30.

5. Новикова М. Л. Книга о языке как информационной системе / М. Л. Новикова // Вопросы теории и практики журналистики. - 2017. - Т. 6, № 2. - С. 254-259. DOI 10.17150/2308-6203.2017.6(2).254-259.

6. Маслова В. А. Когнитивная лингвистика / В. А. Маслова. - М. : ТетраСистемс, 2005. $-256 \mathrm{c}$.

7. Володина М. Н. Когнитивно-информационная природа термина (на материале терминологии средств массовой информации) / М. Н. Володина. - М. : Изд-во МГУ, 2000. - $128 \mathrm{c}$.

8. Рябова Е. А. Информационная природа термина / Е. А. Рябова // Вестник Московского государственного областного университета. Серия: Лингвистика. - 2009. № 4 . - С. 56-57.

\section{REFERENCES}

1. Kalmykov A. A. Medialogiya interneta [Medialogy of the Internet]. Moscow, Librokom Publ., 2013. 272 p.

2. Sukhodolov A. P. Mediology as a Science of the Future (an invitation to continue the discussion started in this journal in 2016). Voprosy teorii $i$ praktik zhurnalistiki $=$ Theoretical and Practical Issues of Journalism, 2017, vol. 6, no. 3, pp. 267-286. (In Russian).

3. Sukhodolov A. P. To Create a Theory of the Media: Statement of the Problem. Voprosy teorii i praktik zhurnalistiki = Theoretical and Practical Issues of Journalism, 2016, vol. 5, no.1, pp. 6-13. (In Russian).

4. Solganik G.Ya. On the Structure and the Most Important Parameters of the Publicistic Style of Speech (the Media Language). Yazyk sovremennoy publitsistiki [Language of Modern Publicistic Writing]. Moscow, Flinta : Nauka Publ., 2005, pp. 13-30.

5. Novikova M. L. A Book about the Language as an Information System. Voprosy teorii i praktik zhurnalistiki $=$ Theoretical and Practical Issues of Journalism, 2017, vol. 6, no. 2, pp. 254-259. (In Russian). 
6. Maslova V. A. Kognitivnaya lingvistika [Cognitive Linguistics]. Moscow, TetraSistems Publ., 2005. 256 p.

7. Volodina M. N. Kognitivno-informatsionnaya priroda termina (na materiale terminologii sredstv massovoy informatsii) [The Cognitive and Information Components of the Term (a Case Study of the Media Terminology)]. Moscow, Moscow State University Publ., 2000. 128 p.

8. Ryabova E. A. Informational Term Nature. Vestnik Moskovskogo gosudarstvennogo oblastnogo universiteta. Seriya: Lingvistika = MRSU magazine. Linguistics, 2009, no. 4, pp. 56-57.

\section{ДЛЯ ЦИТИРОВАНИЯ}

Новикова М. Л. Медиалогия как комплексная наука (прагматический потенциал лингвистических исследований) / М. Л. Новикова // Вопросы теории и практики журналистики. — 2017. — Т. 6, № 4. — C. 643-649. DOI: 10.17150/2308-6203.2017.6(4).643-649.

\section{FOR CITATION}

Novikova M. L. Mediology as a Complex Science (Pragmatic Potential of Linguistic Research). Voprosy teorii i praktiki zhurnalistiki $=$ Theoretical and Practical Issues of Journalism, 2017, vol. 6, no. 4, pp. 643-649. DOI: 10.17150/2308-6203.2017.6(4).643-649. (In Russian). 